\title{
Hemodiyaliz Hemşirelerinde Merhamet Düzeyi ve İlişkili Faktörler
}

\section{The Level of Compassion and Related Factors in Hemodialysis Nurses}

\author{
${ }^{1}$ Özlem ERDEM, ${ }^{2}$ Arzu KOÇAK UYAROĞLU \\ ${ }^{1}$ KTO Karatay Üniversitesi Sağlık Hizmetleri Meslek Yüksekokulu, Konya, Türkiye \\ ${ }^{2}$ Selçuk Üniversitesi Hemşirelik Fakültesi Psikiyatri Hemşireliği Anabilim Dalı, Konya, Türkiye
}

Özlem Erdem: https://orcid.org/0000-0003-3220-166X

Arzu Koçak Uyaroğlu:https://orcid.org/0000-0002-6581-4617

\begin{abstract}
ÖZ
Amaç: Araştırma, hemodiyaliz hemşirelerinin merhamet düzeyini ve ilişkili faktörleri belirlemek amacıyla yapıldı. Materyal ve Metot: Tanımlayıcı ve ilişki arayıcı türde yapılan bu araştırmanın örneklemini Konya il merkezinde yer alan üniversite hastaneleri, Sağlık Bakanlığına bağlı hastaneler ve özel diyaliz merkezlerinde çalışan hemodiyaliz hemşireleri $(\mathrm{n}=85)$ oluşturmaktadır. Verilerin toplanmasında kişisel bilgi formu ve Merhamet Ölçeği (MÖ) kullanıldı. Verilerin değerlendirilmesinde; Mann-Whitney U Testi ve Kruskal Wallis H Testi kullanıldı.

Bulgular: Hemodiyaliz hemşirelerinin merhamet puan ortalamas1 $72,87 \pm 8,27$ olup, sevecenlik alt boyutu puan ortalaması ile çocuk sayısı ve meslekte çalışma yılı arasında ve bilinçli farkındalık alt boyutu puan ortalaması ile hemşirenin diyaliz biriminde çalıșma yılı arasında istatistiksel açıdan anlamlı bir fark olduğu görülmüştür $(\mathrm{p}<0,05)$.

Sonuç: Araştırma sonucunda hemodiyaliz hemşirelerinin merhamet puan ortalamasının orta düzeyde olduğu belirlenmiştir. Çalışmanın daha geniş örneklem üzerinde yapılması önerilmektedir.
\end{abstract}

Anahtar Kelimeler: Hemodiyaliz hemşiresi, hemşirelik, merhamet

\section{ABSTRACT}

Objective: The research was conducted to determine the level of compassion of hemodialysis nurses and related factors.

Materials and Methods: The sample of this descriptive and relationship-seeking study consists of hemodialysis nurses $(n=85)$ working in university hospitals, hospitals affiliated to the Ministry of Health and private dialysis centers located in the city center of Konya. A personal information form and Compassion Scale (MÖ) were used to collect data. In evaluating the data; Mann-Whitney $\mathrm{U}$ Test and Kruskal Wallis H Test were used.

Results: Hemodialysis nurses' mean score of compassion was $72.87 \pm 8.27$, and it was observed that there was a statistically significant difference between the mean score of the compassion sub-dimension and the number of children and years of work in the profession, as well as between the mean score of the conscious awareness sub-dimension and the number of years working in the dialysis unit of the nurses $(\mathrm{p}<0.05)$.

Conclusion: As a result of the research, it was determined that the average score of compassion for hemodialysis nurses was at a medium level. It is recommended that the study be conducted on a larger sample.

Keywords: Compassion, hemodialysis nurse, nursing

\author{
Sorumlu Yazar / Corresponding Author: \\ Özlem Erdem \\ KTO Karatay Üniversitesi Sağlık Hizmetleri Meslek Yüksekokulu, \\ Konya, Türkiye \\ Tel: +90 444 1251-7226 \\ E-mail: ozlem.erdem@karatay.edu.tr
}

Yayın Bilgisi / Article Info:

Gönderi Tarihi/ Received: 18/12/2020

Kabul Tarihi/ Accepted: 30/03/2021

Online Yayın Tarihi/ Published: 05/06/2021

Atıf / Cited: Erdem Ö ve Koçak Uyaroğlu A. Hemodiyaliz Hemşirelerinde Merhamet Düzeyi ve İlişkili Faktörler. Online Türk Sağllk Bilimleri Dergisi 2021;6(2):207-215. doi: 10.26453/otjhs.842847

\section{GİRIS}

Uluslararası Hemşirelik Konseyi tüm hemşirelerin göstermesi gereken beş profesyonel değerden birinin merhamet olduğunu bildirmiştir. ${ }^{1}$ Amerikan Hemşireler Birliği ise etik hükümlerinin 1. maddesindeki "hemşire, mesleki ilişskilerinde, her bireyi, sosyal ve ekonomik statüsü, kişisel özellikleri ya da sağlık problemlerine göre ayırt etmeksizin sinırsız merhamet ile bireylerin kişilik onuruna saygı gösterir." cümlesi ile merhametli bakımın önemini vurgulamıştır. ${ }^{2}$ Sağlık bakımında temel bir değer olan merhamet başkalarının acısını, talihsizliğini anlamak ${ }^{3}$ ve bu acıyı hafifletmeye istekli olmaktır. ${ }^{4}$ 
Birçok tanımı yapılmış olan merhamet; hemşireliğin evrensel ve mükemmel bir bileşeni, ${ }^{5}$ empati kurarak yardım hissinin oluşması olarak kabul edilmekte ${ }^{6}$ ve sağlık profesyonellerinin hastalarına bakım hizmeti sunumunu kolaylaştıran önemli bir değer olarak görülmektedir. $^{7}$

Geriye dönüşümsüz, ilerleyici ve birçok sistemi etkileyebilen kronik böbrek hastalığının tedavisinde sıklıkla kullanılan yöntem olan hemodiyaliz ile hastaların daha rahat ve uzun yaşaması hedeflenmektedir. Böbrek yetmezliğine bağlı olarak gelişen birçok belirti ve bulgular hemodiyaliz tedavisi sayesinde kontrol altına alınmaya çalışılsa da, zorlu tedavi süreci ve makineye bağımlı hale gelme durumu hemodiyaliz hastalarının yaşam kalitesini olumsuz etkilemekte ve diyaliz hastaları tedavi sürecinden kaynaklanan birçok sorunla baş başa kalmaktadır. ${ }^{8,9}$ Sağlık ekibinin en etkin üyesi olan hemşireler diğer kronik hastalıklarda olduğu gibi hemodiyaliz tedavisi gören hasta ve hastanın ailesiyle en fazla vakit geçiren sağlık profesyonelidirler. Uzun süren tedavi sürecinin en önemli destekçilerinden birisi olan hemodiyaliz hemşirelerinin bu süreçte hastaya ve yakınlarına karşı duyarlı ve merhametli davranış göstermesi önemlidir. Yapılan literatür araştırmasında ülkemizde hemodiyaliz hemşirelerinin merhamet düzeyini ve ilişkili değişkenleri inceleyen çalışmalara rastlanmamıştır. Merhametli bakım alan hastaların psikolojik yönden olumlu etkilenerek, kronik hastalığ1 ile daha kolay baş edebileceği ve böylece hastanın yaşam kalitesinin de artacağı düşünülmektedir. Sağlık bakımında merhametin bu denli önemli olması ve literatüre katkı sağlayabileceği düşüncesiyle bu çalışma hemodiyaliz hemşirelerinin merhamet düzeyi ve ilişkili faktörleri belirlemek amacıyla yapılmıştır.

\section{MATERYAL VE METOT}

Araştırmanın Tipi ve Etik: Tanımlayıcı ve ilişki arayıcı araştırma tasarımı ile yürütülmüştür. Çalışmanın etik kurul onayı KTO Karatay Üniversitesi İlaç ve Tıbbi Cihaz Dışı Araştırmalar Etik Kurulu'ndan alınmıştır (Tarih: 20/03/2019, karar Sayısı: 2019/0019). Çalışmada kullanılan ölçek için yazılı izin alınmıştır.

Araştırmanın Yeri ve Zamanı: Araştırma 1 Nisan 2019-31 Haziran 2019 tarihleri arasında Konya'da yer alan Sağlık Bakanlığına bağlı hastaneler, üniversite hastaneleri ve özel diyaliz merkezlerinde gerçekleştirildi.

Evren ve Örneklem: Araştırmanın evreni Konya il merkezinde yer alan üniversite hastaneleri, Sağlık
Bakanlığına bağlı hastaneler ve özel diyaliz merkezlerinde çalışan hemodiyaliz hemşirelerinden $(n=90)$ oluşmakta olup çalışmanın yürütüldüğü tarihlerde kurumda olan ve çalışmaya katılmayı kabul eden hemodiyaliz hemşireleri $(\mathrm{n}=85)$ çalışma grubunu oluşturdu.

Veri Toplama Araçları: Çalışma verileri araştırmac1lar tarafından ilgili literatür çerçevesinde hazırlanan Kişisel Bilgi Formu ve Merhamet Ölçeği kullanilarak toplandi.

Kişisel Bilgi Formu: Form hemodiyaliz hemşirelerinin sosyo-demografik özelliklerini ve çalışma özelliklerini sorgulayan toplam 20 sorudan oluşmaktadır. Merhamet Ölçeği : Pommier ${ }^{10}$ tarafından geliştirilen, Akdeniz ve Deniz ${ }^{11}$ tarafindan Türkçe geçerlik ve güvenirliği yapılan "Merhamet Ölçeği" 24 maddeden oluşmaktadır. Ölçek 5'li likert (1=Hiçbir Zaman, 2=Nadiren, 3=Ara Sira, 4=S1k S1k, 5=Her Zaman) tipindedir. Ölçek sevecenlik $(6,8,16,24)$, umursamazlık $(2,12,14,18)$, paylaşımların bilincinde olma $(11,15,17,20)$, bağlantısızlı $(3,5,10,22)$, bilinçli farkındalık $(4,9,13,21)$ ve ilişki kesme $(1,7,19,23)$ olmak üzere altı alt boyuttan oluşmaktadır. Ölçeğin umursamazlık, bağlantısızlık ve ilişki kesme alt boyutları ters çevrilerek hesaplanır. Bu hesap sonrasında toplam puan ortalaması alınır. Ölçekten alınan toplam puan arttıkça merhamet düzeyi de artmaktadır. Akdeniz ve Deniz'in ${ }^{11}$ çalışmasında ölçeğin Cronbach Alpha değeri 0,85 olarak bulunmuştur. Bu çalışmada Cronbach Alpha değerinin 0,809 olduğu tespit edilmiştir.

Verilerin Toplanması: Çalışmaya başlamadan önce ilgili kurumlardan yazılı onay alınmıştır. Araştırmanın verileri anket uygulama yöntemi ile öz bildirime dayalı olarak toplandı. Hastane ve diyaliz merkezlerinin hemodiyaliz ünitelerinde görev yapan hemşirelere çalışmanın içeriği açıklandıktan sonra sözlü onay vermeleri istenmiştir. Veri toplama araçları, katılımcılara araştırmacının gözetimi altında dağıtılmış ve her bir katılımcının formları doldurması yaklaşık 25 dakika sürmüştür.

Verilerin Değerlendirilmesi: Verilerin analizleri SPSS 20 istatistik paket programında sayı, yüzde, ortalama \pm standart sapma olarak özetlenmiştir. Verilerin değerlendirilmesi Mann-Whitney U Testi, Kruskal Wallis H Testi ve bonferroni düzeltmeli ikili karşılaştırma testleri kullanılarak yapılmıştır.

\section{BULGULAR}

Çalışmaya katılan hemodiyaliz hemşirelerinin \% 81,2'si kadın ve \%76,5'i evlidir. Hemşirelerin \%40'1 
30 yaş altı, \%43,5'i 31-40 yaş arasında, \%16,5'i 41 yaş ve üzerinde olup; katılımcıların yaş ortalaması 33,44 7,3 (21-48) yıldır. Hemşirelerin \%32,9'u lise, \%29,4'ü önlisans, \%37,7'si ise lisans ve lisans üstü programdan mezun olduğu belirlenmiştir. Hemodiyaliz hemşirelerinin \%72,9'u çocuk sahibi olmakla birlikte sahip olunan çocuk sayısı ortalamasının

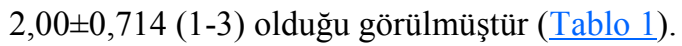

Hemodiyaliz hemşirelerinin \%21,2'si üniversite hastanesinde, \%55,3'ü özel diyaliz merkezinde, \% 23,5'i devlet hastanesinde çalışmakta olduğu ve çalışma yıllarına bakıldığında \%21,1'i $1-5$ yıldır, \% 21,1'i 6-10 yıldır ve \%58,8'i 11 yıldan fazla çalıştığı görülmektedir. Hemşirelikteki ortalama çalışma yılı $11,00 \pm 6,452$ (1-26) yıldır. Hemodiyaliz merkezinde çalışan hemşirelerin \%90,6'sı hemodiyaliz sertifikasına sahip olup, \%56,5'inin gece ve gündüz vardiyasında, \%42,4'ünün gündüz vardiyasında çalıştığ1 saptanmıştır. Hemşirelerin \%78,8'inin mesleğini isteyerek seçtiği, \%87,1'inin işinden memnun olduğu, \% 75,3'ünün başka birime geçmeyi düşünmediği tespit edilmiştir. Hemşirelerin \%55,3'ünün mesleğinden memnun olduğu \%64,7'si son bir yılda işten ayrılmayı düşünmediğini belirtmiştir. Katılımcıların \%61,2'si çalışma yaşamında duygusal zorluk yaşamadığını ifade etmiştir (Tablo 2).

Merhamet ölçeğinden alınan toplam puan ve alt ölçek puanları Tablo 3'de gösterilmiştir. Buna göre hemodiyaliz hemşirelerinin ortalama toplam MÖ

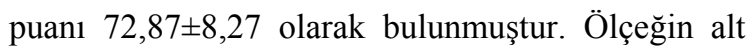
boyutlarının puan ortalamalarına bakıldığında sevecenlik alt boyutunun $17,02 \pm 2,89$, umursamazlık alt boyutunun $7,70 \pm 2,95$, paylaşımların bilincinde olmak alt boyutunun $15,84 \pm 3,13$, bağlantısızlık alt boyutunun $8,09 \pm 2,70$, bilinçli farkındalık alt boyutunun $16,71 \pm 2,59$ ve ilişki kesme alt boyutunun $7,48 \pm 2,65$ olduğu saptanmıştır.

Merhamet ölçeği ve alt ölçeklerden alınan ortalama puanlar, hemşirelerin sosyodemografik ve çalışma özelliklerine göre karşılaştırılmış ve anlamlı bir farklılık olup olmadığını belirlemek amacıyla gerçekleştirilen istatistiksel analiz sonuçları Tablo 4'de sunulmuştur. Merhamet ölçeğinin sevecenlik alt boyutundan alınan puanlar arasında çocuk sayısı değişkeni açısından anlamlı bir farklılık olduğu görülmüştür $(\mathrm{p}<0,05)$. Farkın hangi gruptan kaynaklandığını saptamak için yapılan bonferroni düzeltmeli ikili karşılaştırmalar sonucu 1 çocuğu olanlar ile 3 çocuğu olanlar arasında anlamlı farklılık belirlenmiştir. 1 çocuğu olanların sevecenlik alt boyut puanının, 3 ve üzeri çocuğu olanlara göre daha yüksek olduğu ve aradaki farkın istatistiksel olarak anlamlı olduğu bulunmuştur $(p<0,05)$. Benzer şekilde ölçeğin sevecenlik alt boyutundan alınan puanlar arasında meslekte çalışma yılı değişkeni açısından anlamlı bir farklılık olduğu görülmüştür $(p<0,05)$. Merhamet ölçeğinin bilinçli farkındalık alt boyutunda alınan puanlar arasında diyaliz biriminde çalışma yılı değişkeni açısından anlamlı bir farklılık olduğu görülmüştür $(p<0,05)$. Merhamet ölçeğinden alınan puan ortalamaları ile cinsiyet, medeni durum, eğitim durumu, çocuk sayısı, hemşirelik mesleğinde çalışma yılı ve diyaliz biriminde çalışma yılı değişkenleri açısından anlamlı bir farklılık olmadığı görülmüştür $(\mathrm{p}>0,05)$.

\section{TARTIŞMA VE SONUÇ}

$\mathrm{Bu}$ bölümde hemodiyaliz hemşirelerinin MÖ'den aldıkları puanların farklı değişkenlere göre dağılımı ilgili literatür ışığında ele alınmıştır.

Merhamet ölçeğinden alınabilecek en düşük puan 24 , en yükssek puan ise 120 'dir. Bu ölçek için herhangi bir kesme noktası bulunmamaktadır. Bu çalışmada hemodiyaliz hemşirelerin merhamet ölçeği toplam puan ortalamasının $72,87 \pm 8,27$ olduğu belirlenmiştir. Bu sonuç hemodiyaliz hemşirelerinin MÖ puan ortalamalarının ortalamanın üzerinde olduğunu göstermektedir. Diğer bir ifade ile hemşirelerin merhamet düzeyleri orta seviyededir. Literatür taraması yapılarak çalışmamızda kullanılan merhamet ölçeği ile yapılan çalışmalar incelendiğinde merhamet düzeyinin orta düzeyde ${ }^{12}$ ve yüksek düzeyde ${ }^{13-21}$ olduğunu bildiren çalışmalar mevcuttur. Kaliteli sağlık hizmetinin bir göstergesi sayılan ${ }^{5}$ merhametli bakımı sağlık uygulayıcıların en başında gelen ve hasta ile daha fazla vakit geçiren hemşirelerde bu denli sonuçların oluşması şaşırtıcı olmamıştır. Çünkü hemşirelik mesleği merhamet üzerine kurulmuştur. ${ }^{22}$

Çalışmada ölçek alt boyutları ve genel puanı ile katılımcıların cinsiyet ve medeni durum değişkenleri arasında istatistiksel olarak anlamlı farklılık olmad1ğ1 tespit edilmiştir ( $p>0,05)$. Literatür taraması yapıldığında merhamet ölçeği toplam puanı ile cinsiyet değişkeni arasındaki farkın olmadığı çalışmaların yanısıra $^{12,19}$; kadınlarda merhamet düzeyinin erkek katılımcılara kıyasla yüksek düzeyde olduğunu bildiren çalışmalarda bulunmaktadır. ${ }^{15,23,24}$ Çalışma bulgumuzun literatür ile uyumlu olmamasını erkek katılımcı oranının $(\% 18,8)$, kadın katılımcılara göre az olmasından kaynaklandığını düşünmekteyiz. Cinsiyet yönünden eşit dağılım gösteren gruplarda yap1lacak çalışmalar daha güvenli sonuçlar verecektir. Çalışmada hemşirelik mesleğinde çalışma yılı sorusunun merhamet alt boyutları ile ilişkisine bakıld1- 
ğında sevecenlik alt boyutunun meslekte 11 yll ve üzeri çalışanlarda yüksek çıkmasından dolayı istatistiksel olarak anlamlı düzeyde fark bulunmuştur. Hastalara karşı duyulan sevecenlik unsurunu ifade eden bu alt boyutun mesleki deneyim ilerledikçe artması, hemodiyaliz hemşirelerinin empati duygusunu zamanla kaybetmeden aksine daha da geliştirerek hastalarına sevecen bir ilgiyle yaklaştıklarını düşünmekteyiz.

Yine hemodiyaliz hemşiresi olarak çalışma yılı sorusunun merhamet alt boyutları ile ilişkisine bakıld1ğında bilinçli farkındalık alt boyutunun meslekte 11 yıl ve üzeri çalışanlarda yüksek çıkmasından dolayı istatistiksel olarak anlamlı düzeyde fark bulunmuştur. Bireylerin olumsuz duygularına karşı gösterilen dengeli tavrı ifade eden bu alt boyutun mesleki deneyim ilerledikçe artması; hemodiyaliz hemşirelerinin hastasının çektiği acısının kendisini etkilemesine izin vermeden bu süreci doğru yönetebildiği ile açıklanabilir. Çalışmaya çocuk sayısı değişkeni açısından bakıldığında sevecenlik alt boyut puanlarının bir çocuğu olanlarda, 3 çocuğu olanlara göre yüksek olduğu ve aradaki farkın istatistiksel olarak anlamlı olduğu bulunmuştur $(p<0,05)$. Çocuk sahibi olmanın mesleki alanı ve merhamet duygusunu etkilediğini söyleyebiliriz.

Yardıma muhtaç birey ve ona bakım veren birey arasında adeta köprü görevi yapan ve evrensel bir değer olan merhametin sağlık hizmetlerindeki yeri şüphesiz ki çok önemlidir. Diğer kronik hastalıklarda olduğu gibi hemodiyaliz hastalarına da tedavi aşamasında en yakın temasta bulunan sağlık profesyoneli, hemşirelerdir. Hemodiyaliz hastalarının yaşamlarının sonuna kadar bir makinaya ve tedavi ekibine bağımlı olması sadece hastayı değil ona bakım veren hemşireyi de duygusal anlamda etkileyebilir. Hemşire bu süreci iyi yönetebilecek donanıma sahip olmasının yanında merhamet duygusu ile profesyonel bakımı birleştirerek hastasına bakım sağlamalıdır. Sağlık hizmetlerinde merhametin bu denli önemli olması ve yeterince çalışmaya sahip olamamış olması, merhamet kavramı ve merhametli hasta bakımının önemi hakkında farkındalığın geliştirilebilmesine ihtiyaç olduğunu düşündürmektedir. $\mathrm{Bu}$ amaçla bu çalışmada hemodiyaliz hemşirelerine merhamet ölçeği uygulanmıştır. Çalışmadan elde edilen verilere göre hemodiyaliz hemşirelerinin merhamet düzeyinin orta düzeyde olduğunu ve merhamet düzeyinin çocuk sayısı, hemşirelik mesleğinde çalışma yılı, diyaliz hemşiresi olarak çalışma yılı değişkenleri açısından anlamlı düzeyde fark bulunduğunu, diğer değişkenlerde ise fark bulunmadığını tespit ettik. Hemodiyaliz hemşirelerinin tanımlayıcı özellikleri ile merhamet arasındaki ilişkinin daha iyi bir şekilde ortaya konulabilmesi için aynı çalışmanın daha geniş örneklem üzerinde yapılması, hasta ve tedavisi üzerinde olumlu etkileri olan merhametli bakımın önemine daha çok dikkat çekmek adına nitel çalışmalar yapılarak derinlemesine incelenmesi ve sağlık alanında farklı branşlar ve değişkenlerle çalışmaların yapılması önerilebilir.

Çalışmanın, yalnızca Konya ili üniversite hastaneleri, Sağlık Bakanlığına bağlı hastaneler ve özel diyaliz merkezlerinde çalışan hemodiyaliz hemşirelerine genellenebilir olması bu araştırmanın sınırlılığıdır. Araştırma sonucunda elde edilen bulguların hemodiyaliz hemşirelerinin kendi ifadelerine dayalı olması araştırmanın bir diğer sınırlılı̆̆ıdır.

Etik Komite Onayı: Araştırma KTO Karatay Üniversitesi İlaç ve Tıbbi Cihaz Dışı Araştırmalar Etik Kurulu tarafindan onaylandi (Tarih: 20/03/2019, karar no: 2019/0019).

Çıkar Çatışması: Yazarlar çıkar çatışması bildirmemektedir.

Yazar Katkıları: Fikir-AKU; Veri toplanması ve/ veya işlemesi-ÖE; Analiz ve/veya yorum-AKU, ÖE; Yazıyı yazan-AKU, ÖE.

Hakem değerlendirmesi: Dış bağımsız.

Teşekkür: Yazarlar, araştırmaya katılan tüm hemodiyaliz hemşirelerine teşekkür eder.

Diğer: Bu araştırma 6.Uluslararası 17.Ulusal Hemşirelik Kongresi, 19-21 Aralık 2019, Ankara'da sözlü bildiri olarak sunulmuştur.

\section{KAYNAKLAR}

1. International Council of Nurses. Revised 2012. The ICN code of ethics for nurses. 2012.https:// www.icn.ch/sites/default/files/inlinefiles/2012_ICN_Codeofethicsfornurses_\% 20eng.pdf. Erişim tarihi 15 Aralık 2020.

2. American Nurses Association. Code of ethics fornurses with interpretive statements. First published:January, Maryland, 2015. https:// www.nursingworld.org/practice-policy/nursingexcellence/ethics/code-of-ethics-for-nurses/coeview-only/. Erişim Tarihi:15 Aralık 2020.

3. Van der Cingel M. Compassion in care: a qualitative study of older people with a chronic disease and nurses. Nursing Ethics. 2011;18(5):672685.

4. Schantz ML. Compassion: A concept analysis. Nursing Forum. 2007;42(2):48-55. 
5. Uğurlu AK, Eti Aslan F. Merhamet ve hemşirelik: merhamet ölçülebilir mi? Türkiye Klinikleri Hemsirelik Bilimleri. 2017;9(3):233-238. doi:10.5336/nurses.2016-53677

6. Burnell L, Agan DL. Compassionate care: Can it be defined and measured? The development of the compassionate care assessment tool. International Journal of Caring Sciences. 2013;6(2):180187.

7. Bektaş G, Genç G, Güneç A, Aytaç B. Sağlık çalışanlarında merhamet yorgunluğu. 2nd International Symposium Humanities and Social Sciences. 04-07 Ağustos 2018, Comrat / Moldova.

8. Topbaş E, Bingöl G. Psikososyal boyutu ile diyaliz tedavisi ve uyum sürecine yönelik hemşirelik girişimleri. Türk Nefroloji, Diyaliz ve Transplantasyon Hemşireleri Derneği Nefroloji Hemşireliği Dergisi. 2017;12(1):36-42.

9. Şanlitürk D, Ovayolu N, Kes D. Hemodiyaliz hastalarında sık karşılaşılan problemler ve çözüm önerileri. Türk Nefroloji, Diyaliz ve Transplantasyon Hemşireleri Derneği Nefroloji Hemşireliği Dergisi. 2018;1(13):17-25.

10. Pommier EA. The compassion scale. The University of Texas at Austin, Doctoral dissertation. Texas, United States. 2010.

11. Akdeniz S, Deniz ME. Merhamet ölçeğinin Türkçeye uyarlanması: geçerlik ve güvenirlik çalışması. The Journal of Happiness and WellBeing. 2016;4(1):50-61.

12. Özdelikara A, Babur S. Hemşirelik öğrencilerinin merhamet düzeyi ve empatik eğilim ilişkisi. ACU Sağlık Bil Dergisi. 2020;11(2):342-349. doi: 10.31067/0.2020.271

13. Çınar F, Eti Aslan F. Ameliyathane hemşirelerinin merhamet düzeylerinin ölçülmesi: Türkçe geçerlilik ve güvenilirlik çalışması. Kocaeli Tıp Dergisi. 2018;7(3): 222-229.

14. Arlı ŞK, Bakan AB. Cerrahi hemşirelerde merhamet ve kültürlerarası duyarlılığı etkileyen faktörler. STED/Sürekli Tıp Eğitimi Dergisi. 2018;27(4): 277-283.

15. Çingöl N, Çelebi E, Zengin S, Karakaş M. Bir sağlık yüksekokulu hemşirelik bölümü öğrencilerinin merhamet düzeylerinin incelenmesi. Klinik Psikiyatri Dergisi. 2018;21:61-67.

16. Seven A, Doğan SG, Kınık A ve ark. Compassion levels of the intern students of nursing and the influencing factors: pilot study. Online Türk Sağlık Bilimleri Dergisi. 2019;4(3):273-282.

17. Demirel G, Kaya N, Doğaner A. Ebelik öğrencilerinin kültürlerarası yaklaşımlarının merhamet ve empati düzeylerine etkisi. OPUS Uluslararas1 Toplum Araştırmaları Dergisi. 2020;15(21):284300. doi:10.26466/opus.591200

18. Cingi CC, Eroğlu E. Sağlık çalışanlarında merhamet yorgunluğu. Osmangazi Tıp Dergisi. 2019;41(1):58-71. doi:10.20515/otd.449810

19. Arkan B, Y1lmaz D, Düzgün F. Determination of compassion levels of nurses working at a university hospital. Journal of Religion and Health. 2019. doi:10.1007/s10943-019- 00786-x

20. Hacıkeleşoğlu AGH, Kartopu S. Merhamet ve dindarlık: Üniversite öğrencileri üzerine ampirik bir araştırma. The Journal of Academic Social Science Studies. 2017;59:203-227. doi:10.9761/ JASSS7234

21. Salazar LR. Exploring the relationship between compassion, closeness, trust, and social support in same-sex friendships. The Journal of Happiness and Well-Being. 2015;3(1):15-29.

22. Waldrop J. Compassion needed for all. The Journal for Nurse Practitioners. 2020. doi:10.1016/ j.nurpra.2020.04.003

23. Gündüzoğlu NÇ, Akon Korhan E, Kuzeyli Yıldırım Y, Şenuzun Aykar F, Üstün Ç. Hemşirelik öğrencilerinde merhamet düzeyi. Journal of Human Rhythm. 2019;5(2):103-116.

24. Tatum KJ. Adherence to gender roles as a predictor of compassion and self-compassion in women and men. Graduate Faculty of Baylor University. Doctoral dissertation. United States. 2012. 
Tablo 1. Hemodiyaliz hemşirelerine ait sosyo-demografik özellikler.

\begin{tabular}{|c|c|c|c|}
\hline & Değişken (n=85) & $\mathbf{n}$ & $\%$ \\
\hline \multirow[t]{3}{*}{ Yaş } & 30 yaş ve altı & 34 & 40,0 \\
\hline & $31-40$ yaş arası & 37 & 43,5 \\
\hline & 41 yaş ve üzeri & 14 & 16,5 \\
\hline \multirow[t]{2}{*}{ Cinsiyet } & Kadın & 69 & 81,2 \\
\hline & Erkek & 16 & 18,8 \\
\hline \multirow[t]{2}{*}{ Medeni durum } & Evli & 65 & 76,5 \\
\hline & Bekar, boşanmış & 20 & 23,5 \\
\hline \multirow[t]{3}{*}{ Mezun olunan okul } & Lise & 28 & 32,9 \\
\hline & Önlisans & 25 & 29,4 \\
\hline & Lisans ve üstü & 32 & 37,7 \\
\hline \multirow[t]{2}{*}{ Çocuk varlığı } & Evet & 62 & 72,9 \\
\hline & Hayır & 23 & 27,1 \\
\hline \multirow[t]{3}{*}{ Çocuk sayısı } & 1 çocuk & 17 & 27,4 \\
\hline & 2 çocuk & 34 & 54,8 \\
\hline & 3 ve üzeri çocuk & 11 & 17,7 \\
\hline
\end{tabular}


Tablo 2. Hemodiyaliz hemşirelerine ait çalışma özellikleri.

\begin{tabular}{|c|c|c|c|}
\hline & Değişken $(\mathrm{n}=85)$ & $\mathbf{n}$ & $\%$ \\
\hline \multirow[t]{3}{*}{ Çalıştığı Kurum } & Devlet hastanesi & 20 & 23,5 \\
\hline & Üniversite hastanesi & 18 & 21,2 \\
\hline & Özel merkez & 47 & 55,3 \\
\hline \multirow[t]{3}{*}{ Hemşirelikteki mesleki yılı } & $1-5 \mathrm{y} 1 \mathrm{l}$ & 18 & 21,1 \\
\hline & $6-10 \mathrm{y} 11$ & 17 & 21,1 \\
\hline & 11 ve üzeri çalışma yılı & 50 & 58,8 \\
\hline \multirow[t]{3}{*}{ Hemodiyalizde çalışma yılı } & $1-5 \mathrm{y} 1 \mathrm{l}$ & 31 & 36,5 \\
\hline & 6-10 y1l & 26 & 30,5 \\
\hline & 11 ve üzeri çalışma yılı & 28 & 33 \\
\hline \multirow[t]{2}{*}{ Sertifika varlığı } & Evet & 77 & 90,6 \\
\hline & Hayır & 8 & 9,4 \\
\hline \multirow[t]{3}{*}{ Çalışma şekli } & Gündüz vardiyası & 36 & 42,4 \\
\hline & Gece vardiyas1 & 1 & 1,2 \\
\hline & Gece ve gündüz vardiyas1 & 48 & 56,5 \\
\hline \multirow[t]{2}{*}{ Mesleği isteyerek seçme } & Evet & 67 & 78,8 \\
\hline & Hayır & 18 & 21,2 \\
\hline \multirow{2}{*}{ İşten memnuniyet } & Evet & 74 & 87,1 \\
\hline & Hayır & 11 & 12,9 \\
\hline \multirow[t]{2}{*}{ Başka birime geçme düşüncesi } & Evet & 21 & 24,7 \\
\hline & Hayır & 64 & 75,3 \\
\hline \multirow[t]{2}{*}{ Hemşireliği yeniden seçmeyi isteme } & Evet & 47 & 55,3 \\
\hline & Hayır & 38 & 44,7 \\
\hline \multirow[t]{2}{*}{ Son bir yılda işten ayrılmayı düşünme } & Evet & 30 & 35,3 \\
\hline & Hayır & 55 & 64,7 \\
\hline \multirow{4}{*}{$\begin{array}{l}\text { Hangi sıklıkta işten ayrılmayı düşünüyorsu- } \\
\text { nuz }\end{array}$} & Her zaman & 2 & 6,5 \\
\hline & S1k s1k & 6 & 19,4 \\
\hline & Bazen & 16 & 51,6 \\
\hline & Nadiren & 7 & 22,6 \\
\hline \multirow[t]{2}{*}{ Duygusal zorluk yaşama } & Evet & 33 & 38,8 \\
\hline & Hayır & 52 & 61,2 \\
\hline \multirow[t]{5}{*}{ Bunaldığınızda kendinizi rahatlama yolu } & Müzik & 14 & 16,5 \\
\hline & Sohbet & 16 & 18,8 \\
\hline & Sessiz ortamda dinlenme & 19 & 22,4 \\
\hline & Çay-kahve-sigara & 34 & 40,0 \\
\hline & Diğer & 2 & 2,4 \\
\hline
\end{tabular}


Tablo 3. Hemodiyaliz hemşirelerinin merhamet ölçeği ve alt boyutlarına ait tanımlayıcı istatistikler.

\begin{tabular}{|l|c|c|c|c|c|}
\hline Değişkenler & Mean & SD & Median & Min. & Max. \\
\hline Sevecenlik & 17,02 & 2,89 & 18,0 & 8,0 & 20,0 \\
\hline Umursamazlık* & 7,70 & 2,95 & 7,0 & 4,0 & 16,0 \\
\hline Paylaşımların Bilincinde Olmak & 15,84 & 3,13 & 17,0 & 7,0 & 20,0 \\
\hline Bağlantısızlı** & 8,09 & 2,70 & 7,0 & 4,0 & 16,0 \\
\hline Bilinçli Farkındalık & 16,71 & 2,59 & 17,0 & 9,0 & 20,0 \\
\hline İlişki Kesme* & 7,48 & 2,65 & 7,0 & 4,0 & 17,0 \\
\hline Merhamet Ölçeği (toplam puan) & 72,87 & 8,27 & 73,0 & 51,0 & 98,0 \\
\hline
\end{tabular}

*Toplam puan ortalaması hesaplanırken ters puanlanmıştır. 


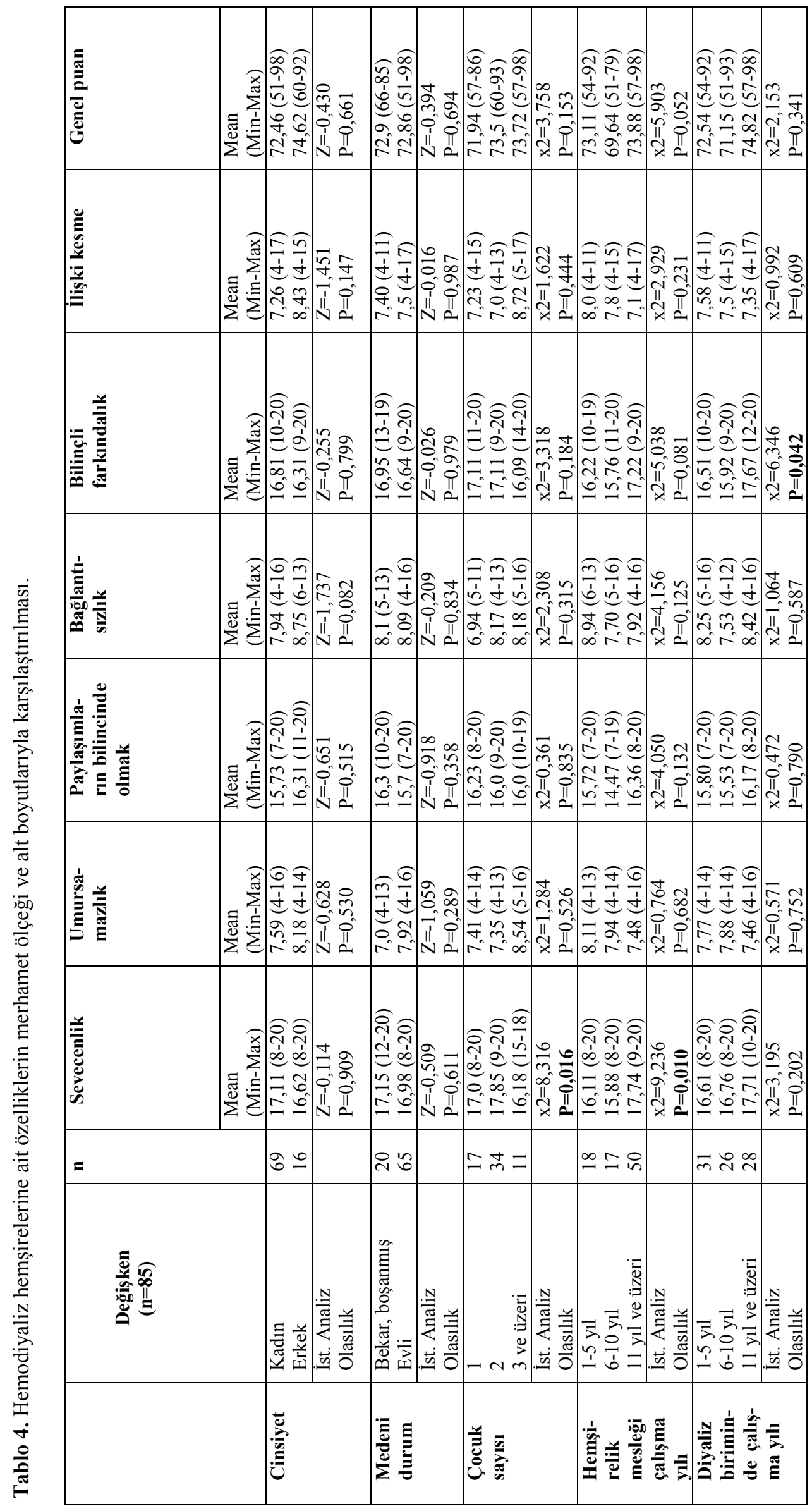

